\title{
Exploring sleep disorders in patients with chronic kidney disease
}

This article was published in the following Dove Press journal:

Nature and Science of Sleep

\author{
Gaurav Nigam' \\ Macario Camacho ${ }^{2}$ \\ Edward T Chang ${ }^{2}$ \\ Muhammad Riaz ${ }^{3}$ \\ 'Division of Sleep Medicine, Clay \\ County Hospital, Flora, IL, ${ }^{2}$ Division \\ of Otolaryngology, Sleep Surgery and \\ Sleep Medicine, Tripler Army Medical \\ Center, Honolulu, HI, ${ }^{3}$ Division of \\ Sleep Medicine, Astria Health Center, \\ Grandview, WA, USA
}

\begin{abstract}
Kidney disorders have been associated with a variety of sleep-related disorders. Therefore, researchers are placing greater emphasis on finding the role of chronic kidney disease (CKD) in the development of obstructive sleep apnea and restless legs syndrome. Unfortunately, the presence of other sleep-related disorders with CKDs and non-CKDs has not been investigated with the same clinical rigor. Recent studies have revealed that myriad of sleep disorders are associated with CKDs. Furthermore, there are a few non-CKD-related disorders that are associated with sleep disorders. In this narrative review, we provide a balanced view of the spectrum of sleep disorders (as identified in International Classification of Sleep disorders-3) related to different types of renal disorders prominently including but not exclusively limited to CKD.

Keywords: kidney disease, sleep disorders, obstructive sleep apnea, parasomnias, restless legs syndrome, chronic kidney disease, insomnia
\end{abstract}

\section{Introduction}

Patients with kidney disorders are afflicted with various types of sleep disorders. At times, primary care providers may fail to identify the type of sleep disorder unless they are aware of the common co-existing sleep-related comorbidities to look for in patients with kidney disorders. In this narrative review, we will discuss the most common sleep disorders seen in patients with various kidney disorders with a primary focus on chronic kidney disease (CKD). The Kidney Disease Improving Global Outcomes (KDIGO) Work Group defines CKD as the presence of any prominent marker of kidney damage (such as albuminuria) or the glomerular filtration rate of less than $60 \mathrm{~mL} / \mathrm{min} / 1.73 \mathrm{~m}^{2}$ for a duration lasting 3 months or longer. ${ }^{1}$ Classically, restless legs syndrome (RLS) and obstructive sleep apnea (OSA) have been associated with CKD with little mention of other sleep disorders. ${ }^{2,3}$ However, patients with CKD appear to experience a myriad of sleep disorders including but not limited to RLS and OSA. ${ }^{4}$ In addition, non-CKDrelated renal disorders could be associated with some sleep disorders. We define non-CKD-related renal disorders as any renal disorder (either of renal parenchyma or collecting system) that falls out of the KDIGO definition for CKD. In the next sections, we categorically discuss the most common sleep disorders as classified by the International Classification of Sleep Disorders 3 (ICSD-3) related to kidney disorders.

\section{Insomnia}

ICSD-3 defines insomnia as "a repeated difficulty with sleep initiation, duration, consolidation, or quality that occurs despite adequate opportunity and circumstances
Correspondence: Gaurav Nigam Division of Sleep Medicine, Clay County Hospital, 9I I Stacy Burk Drive, Flora, IL 62839, USA

Tel + I 6186622131

Email dr.nigamgaurav@gmail.com 
for sleep, and results in some form of daytime impairment". 5 Patients with insomnia typically experience difficulty falling asleep, staying asleep, and/or undesired sustained periods of wakefulness during normal sleep periods. ${ }^{6,7}$ Previous studies have identified both cognitive and physiological risk factors of insomnia. ${ }^{7}$ Among the physiological risk factors, kidney dysfunction likely leads to an imbalance of various metabolites influencing sleep, which might cause abnormalities in sleep. ${ }^{8-10}$

In patients with kidney disease, progression to CKD or end stage renal disease (ESRD) appears to be correlated with the development of various sleep disorders. ${ }^{9,10}$ Several studies have evaluated the effects of kidney disease on sleep disturbances and sleep disorders upon escalating to CKD or ESRD status. ${ }^{9-15}$ Though the reported data from these studies fluctuated widely in type (i.e. subjective vs. objective) of the parameter described, these studies mostly concurred that a direct linear relationship (correlation) exists between CKD or ESRD and insomnia. Specifically, worsening CKD or ESRD correlated directly with worsening insomnia as defined by the full gamut of the sleep cycle to include but not limited to sleep onset and duration of sleep. ${ }^{9-15}$

Kidney dysfunction might be associated with profound effects on physiological functions. ${ }^{12-15}$ It leads to the development of CKD or ESRD which in turn causes disturbances in normal homeostasis affecting sleep. Several studies evaluating efficacy of dialysis in patients with CKD or ESRD reported findings that appear to strengthen the association between kidney dysfunction and sleep disorders. ${ }^{16-22}$ Another study evaluated different types of dialysis and their effects on sleep disorders. ${ }^{23}$ Furthermore, some studies suggest that dialysis is associated with worsening parameters of normal sleep. ${ }^{17-20}$ These studies also identified and confirmed the direct physiological correlation between CKD or ESRD and insomnia. A comprehensive review by Parker defined this relationship between insomnia and kidney disease in addition to other diseases within the spectrum of sleep disorders. ${ }^{16}$ Ineffective glomerular filtration leads to an inability to maintain homeostasis with respect to various metabolic products including vital bioelements and proteins. ${ }^{24}$ This dysregulation in homeostasis might impact sleep in various ways. ${ }^{18-24}$

To further delineate the specific etiology, we discuss two etiologies, namely, elevated levels of orexins and hypercalcemia, as they are related to insomnia. Rayner ${ }^{25}$ proposed a direct link between orexin or hypocretin levels and insomnia. Orexin has been linked to arousal, wakefulness, and appetite. ${ }^{26}$ A lack of orexin (hypocretin) leads to a disorder of diminished wakefulness, narcolepsy. ${ }^{27}$ Rayner proposed that in patients with CKD or ESRD, the body's physiological levels of orexin reaches abnormal levels leading to increased periods of wakefulness that can be associated with insomnia. ${ }^{25}$ Similarly, according to Virga et al, hypercalcemia, which is typically associated with CKD or ESRD, can cause insomnia. ${ }^{28}$ Moreover, kidney dysfunction leads to hypercalcemia which in turn leads to psychiatric overtones typically associated with hypercalcemia such as anxiety, depression, psychosis, and insomnia. ${ }^{29}$

In addition, calcium mediates a variety of known and unknown signaling pathways in humans. It serves as a co-factor and facilitates normal physiological processes to maintain homeostasis. In patients with CKD who have severe hyperparathyroidism, treatment of hypercalcemia (via parathyroidectomy) appears likely to alleviate insomnia. ${ }^{30}$ In addition, calcium and orexin might be correlated as well. ${ }^{31}$ Scientists hypothesize that the increased levels of calcium is indirectly involved in a number of signaling pathways that affect sleep including the orexin (hypocretin) signaling pathway rather than considering a direct link between calcium and sleep cycle. Further studies are highly warranted to accurately identify the role of calcium and orexin with respect to sleep and to identify any correlation between the two.

\section{Sleep-related breathing disorders Obstructive sleep apnea}

OSA is a sleep disorder in which apneas (complete or near complete cessation of airflow), hypopneas (partial airway obstruction), or respiratory effort-related arousals (RERAslimited airway obstruction with an associated arousal) are seen. Kidney disease has been found to have an association with OSA. It has been demonstrated that in critically ill patients, the subset of patients with OSA had a higher risk of incidence of acute kidney injury compared to those who were critically ill but did not have a diagnosis of OSA $(57 \%$ vs. $41 \%) .{ }^{32}$ OSA is estimated to be present in approximately $20 \%$ of the male and $10 \%$ of the female patients with ESRD. ${ }^{33}$ Mild CKD has been found to be associated with arousals during sleep as well as with severe OSA. ${ }^{34}$ According to a study, the change in position in patients with OSA from upright to supine can narrow the upper airway volume by about 33\%. ${ }^{35}$ Therefore, anything that additionally narrows the upper airway can predispose patients to a worsening of their preexisting OSA. Patients with kidney disease can have 
significant accumulation of fluid throughout their body, and when they lie down to sleep, they may have migration of the fluid to their upper airway, in a phenomenon known as rostral overnight fluid shifting. ${ }^{36}$ As CKD worsens and there is more and more fluid accumulation, the apnea-hypopnea index (AHI) can increase. Methods that can reduce the accumulated fluid can help to improve OSA, as demonstrated by hemodialysis (HD) on responders showing an improvement in AHI value of 42.5-7.3 events/hour; however, in non-responders, the value changed minimally from 37.1 to 38.1 events/hour). ${ }^{37}$ As an example of improvement in AHI after kidney transplantation, in 8 responders, the AHI value improved from 21 to 4.5 events/hour, whereas in non-responders, it remained unchanged (from 22 to 20 events/hour) ${ }^{38}$ Similar to patients with $\mathrm{CKD}$, those with nephrotic syndrome can have nocturnal rostral fluid shifting, which can improve with treatment. Tang et al demonstrated that in patients treated with steroids for primary nephrotic syndrome and lower limb edema, there was a decrease in AHI value from 17.3 to 8.7 events/hour. ${ }^{39}$

\section{Hypoventilation}

There is a very intimate relationship between the kidneys and the lungs. For adults, sleep hypoventilation is scored when the arterial PCO2 (or surrogate) is $>55 \mathrm{~mm} \mathrm{Hg}$ for $\geq 10$ minutes or there is an increase in the arterial PCO2 (or surrogate) $\geq 10 \mathrm{~mm} \mathrm{Hg}$ (in comparison to an awake supine value) to a value exceeding $50 \mathrm{~mm} \mathrm{Hg}$ for $\geq 10$ minutes. ${ }^{40}$ Hypoventilation can occur in patients with kidney disease. Acid-base disturbances are corrected and compensated by both the lungs and the kidneys, as calculated by the HendersonHasselbalch equation $(\mathrm{pH}=\mathrm{pK}+\log$ (base concentration/ acid concentration)). ${ }^{41}$ The lungs regulate $\mathrm{PaCO}_{2}$ and the kidneys regulate $\mathrm{HCO}_{3}-{ }^{42}$ Therefore, when a patient has both hypoventilation and kidney disease, there can be acid-base disturbances beyond what would be expected in a patient without kidney disease. A recent case report could be indicative of the relationship between hypoventilation and kidney function in a patient with focal segmental glomerulosclerosis (FSG). In this particular patient with OSA, the FSG resolved with bi-level positive airway pressure therapy even though his weight did not change (i.e. he continued to display morbid obesity). ${ }^{43}$

\section{Central sleep apnea}

Central sleep apnea (CSA) is broadly defined as the occurrence of $\geq 5$ episodes of airflow obstruction due to central apnea and/or central hypopnea per hour of sleep; it is char- acterized by $>50 \%$ of the episodes of central apneas and/or central hypopneas of the total observed apneas and hypopneas along with subjective symptoms of sleep apnea (such as sleepiness, awakening with shortness of breath, snoring, witnessed apneas, or insomnia). ${ }^{5}$ Several pathophysiological pathways contribute to the development of central apneas in patients with CKD. Some of the reported mechanisms include (but are not limited to) the development of interstitial pulmonary edema, chronic metabolic acidosis, and compromised clearance of uremic toxins. ${ }^{44}$

A recent systematic review reported an aggregate point prevalence of CSA in patients with CKD of about $9.6 \%$, although the estimated range was highly variable between 0 and $75 \% .{ }^{45}$ Could this estimated prevalence be an underestimation? Inclusion of central hypopnea indices helps to identify the prevalence of CSA more accurately. The aggregate point prevalence of CSA in CKD when selecting only those studies that reported total CSA index (i.e. including both central apnea and central hypopnea indices) shoots up to $33.3 \%$, a numeric value that is substantially higher than the conservative aggregate point prevalence of $9.6 \%$ (arrived at by including studies that do and do not include central hypopnea index). ${ }^{45,46} \mathrm{CKD}$ is increasingly appearing as an independent risk factor for CSA. Limited evidence suggests that even after adjustment for cardiovascular comorbidities, CKD could be independently associated with $\mathrm{CSA}^{47}$ In studies that recruited patients with both congestive heart failure $(\mathrm{CHF})$ and $\mathrm{CKD}$, the prevalence of CSA varied between 22 and 27\%. ${ }^{47-49}$ Unfortunately, these studies did not disclose what proportion of patients with CHF had systolic or diastolic heart failure. In patients with CKD, after adjustment for non-modifiable risk factors (such as age and gender) and modifiable risk factors (such as basal metabolic index, hypertension, diabetes mellitus, and smoking status), CKD stage III and New York Heart Association class $\geq$ III were found to be predictive of CSA index. ${ }^{47}$ In a non-dialyzed population, CKD was found to be associated with CSA and severe sleep disordered breathing (SDB). The prevalence of CSA in patients with CKD might be as high as 2.9 times after adjustment for modifiable risk factors such as age, sex, and obesity. ${ }^{50} \mathrm{CSA}$ was found to be an independent risk factor for all-cause mortality, and SDB conferred greater risk of mortality in patients with $\mathrm{CKD}$ compared to patients without CKD.${ }^{50} \mathrm{CSA}$ may contribute to rapid worsening of renal function in patients with $\mathrm{CKD}$, which might be one of the major reasons for the increase in all-cause mortality. Nocturnal HD and renal transplantation 
appear to be reasonable treatment options for treatment of CSA in patients with CKD depending on disease severity and patient acceptability. ${ }^{51}$

\section{Central disorders of hypersomnolence}

The etiology of hypersomnia in renal disease is multifactorial, which is contributed by many factors including high prevalence of SDB, RLS, and Parkinson's disease or its treatment side-effects, uremic encephalopathy, nonadherence to immunosuppressive therapy in renal transplant patients, rapid fluid shift and $\mathrm{pH}$ changes, electrolyte imbalance, and inflammatory cytokines associated with dialysis. ${ }^{52,53}$ Prevalence of central disorders of hypersomnia is not well reported in patients with renal disease. Studies are scarce on the determination of association between renal disease and disorders of central hypersomnolence such as narcolepsy, idiopathic hypersomnia, or Klein Levin syndrome. Ezzat and Mohab reported a prevalence of narcolepsy in dialysis-dependent patients with CKD of about $1.4 \%$ and $1 \%$ in patients with non-dialysis CKD which is much higher than that of general population. ${ }^{14}$ Inflammatory cytokine levels are usually high in patients with CKD, and tumor necrosis factor alpha (TNF-alpha) has been associated with narcolepsy. ${ }^{54,55}$ However, the role of TNF-alpha in renal disease has not been well studied. Therefore, further research is needed to confirm this which could provide useful information regarding CKD and narcolepsy. Given the relative rarity of central disorders of hypersomnolence and the lack of studies delineating their prevalence, excessive daytime sleepiness (EDS) remained the most common manifestation of hypersomnia in patients with renal disease. In addition, SDB is the most common cause of EDS in patients with renal disease with prevalence observed as high as $50 \%$ in some studies. This high prevalence can be primarily attributed to unstable ventilatory control and upper airway blockage aggravated by fluid shifts during sleep..$^{10,56,57}$ Although only some patients experience EDS due to SDB, the prevalence of EDS in renal disease is even higher which suggests that other etiologies of sleepiness are involved besides SDB. ${ }^{9,52}$ According to some studies, the prevalence of EDS in patients with CKD, in patients undergoing dialysis, and those who underwent renal transplantation varies between 44 and 67\%. ${ }^{57-60}$ Patients undergoing HD are even more somnolent due to many reasons including ventilatory instability, decreased sleep efficiency, less slow wave sleep, and rapid eye movement (REM) sleep. ${ }^{61}$ This might lead to poor sleep quality at night time and consequently the patients experience increased daytime sleepiness independent of SDB. Parker et al studied a group of patients undergoing HD for objective sleepiness using multiple sleep latency test (MSLT). ${ }^{62}$ They found that $13 \%$ of the patients had pathologic hypersomnolence with an MSLT score of $>5$ minutes. A significant number of patients were found to have REM sleep on at least one nap, and only $11 \%$ variance in sleepiness measures correlated with respiratory disturbance index (RDI) suggesting that other causes of sleepiness are involved besides SBD. ${ }^{62}$ It appears that EDS is not exclusively confined to adults; almost $60 \%$ of the children undergoing dialysis in the age group of 6-20 years also reported EDS as their main sleep-related complaint. ${ }^{63}$ It is imperative to identify sleepiness in patients with CKD, particularly in those who are undergoing HD as one study reported a correlation between the degree of sleepiness and survival. ${ }^{64}$ Other comorbid psychiatric disorders with high prevalence in renal disease such as depression and polypharmacy should be screened as these can also contribute to sleepiness independent of sleep-related disorders. ${ }^{65,66}$ As the treatment for excessive sleepiness depends on the underlying etiology, comprehensive sleep evaluation including detailed medical history, physical exam, and polysomnography should be performed and sleepiness questionnaire must be evaluated to identify such patients. Successful treatment of sleepiness can lead to overall improvement in quality of life and prevent significant morbidity.

\section{Circadian rhythm sleep-wake disorders}

The word "circadian" is derived from the Latin words circa, meaning "around" and diēm, meaning "day". The term "circadian" alludes to vital biological processes that occur continuously with an approximate 24-hour periodicity. Circadian rhythms in renal physiology have been studied for over 150 years. Edward Smith has been credited to have described the existence of circadian rhythmicity in renal excretion of urea and water. ${ }^{67}$ One of the pioneering works in the field of "kidney clocks" was conducted by Mills and Stanbury. They selected five subjects between the ages of 20 and 36 years with no preexisting renal disorders. The subjects spent a total of 48 hours doing identical routine activities comprising short periods of eating, sleeping, and analytical activities during illumination that was recurring every 12 hours. A persistent 24-hour rhythm was detected in the urinary output of water, sodium, potassium, chloride, and urinary $\mathrm{pH} .{ }^{68}$ When the preexisting light/dark cycle and the feeding/fasting schedule was reversed, the expression of clock genes in animal kidney models undergo a prominent phase shift. ${ }^{69}$ 
Melatonin is one of the most extensively studied markers of the circadian sleep-wake cycle. It is generated by pineal gland at night, a phenomenon called as dim light melatonin onset (DLMO). Exposure to bright light suppresses the production of melatonin. DLMO cannot be reliably used as a marker of circadian rhythm in patients with renal transplant due to the exceeding low baseline values in a substantial proportion of such patients. ${ }^{70}$ The circulating levels of melatonin gradually decreases with age, but the circadian rhythm with its nocturnal increase is preserved with age. The baseline amplitude of circadian rhythm decreases with deteriorating renal function. ${ }^{71}$ Consequently, the nocturnal surge in melatonin is absent in patients suffering from ESRD undergoing HD. ${ }^{72}$ While melatonin rhythm may be absent in ambulatory peritoneal dialysis and conventional daytime patients with $\mathrm{HD}$ it re-establishes itself in nocturnal patients with $\mathrm{HD},{ }^{73}$ at least partially. ${ }^{74}$ It remains unclear if the re-establishment of sleep-wake circadian pattern and restoration of melatonin rhythm stems from improved effectiveness of dialysis (resulting from better clearance of pharmaceutical agents and toxins) during night-time or the inherent circadian effect of that particular time on the 24-hour clock for dialysis treatment.

Patients with CKD have a pathological non-dipping blood pressure pattern. They often have poor renal tubular concentrating ability, which may result in nocturia. More than $30 \%$ of the non-dippers with type 2 diabetes treated with melatonin were restored to the normal circadian rhythm of blood pressure. ${ }^{75}$ Chronotherapy, the timed administration of pharmaceutical agents with respect to an individual's circadian rhythms, is emerging as a promising branch of applied circadian pharmacology. By capturing this cyclical pattern of urinary metabolites, chronotherapy enhances the therapeutic effectiveness and mitigates dose-related adverse effects.

Metabolic syndromes such as hypertension and diabetes, and to a lesser extent obesity are classical risk factors of CKD. ${ }^{76}$ An earlier systematic review cited insufficient evidence linking shift-based work to the subsequent development of metabolic syndrome. ${ }^{77}$ However, few recent studies claim incontrovertible evidence linking shift-based work to metabolic syndromes. ${ }^{78-80}$ Of note, one meta-analysis suggested that night shift work is significantly associated with the risk of metabolic syndrome, particularly with longer shift durations. ${ }^{81}$

\section{Parasomnias}

Parasomnias are unwanted behaviors during sleep or during transitions between different stages of sleep or during sleepwake transitions. While the definitive etiologies could include genetic and familial predispositions and in some cases localized lesions of brain stem, a common factor appears to be malfunctioning in case of arousal mechanisms during sleep, which leads to the genesis of parasomnias. ${ }^{82-84}$ This "myoencephalographic dissociation" alludes to activation of the motor component of the awake state while demonstrating electroencephalography electrical activity (i.e., dissociated state) of sleep stages. These parasomnias can be categorized as simple or complex. Simple parasomnias only involve one body area and are usually restricted to singular movements. Complex parasomnias are more bizarre behaviors, which can be disruptive of sleep and have the potential of harm to self or bed partner. Complex parasomnias have been divided into three main categories: REM sleep-related, non- REM sleeprelated, and other parasomnias. ${ }^{85}$ Prevalence of parasomnias are not well studied; however, some studies have reported prevalence of some non-REM parasomnias between 2 and $4.2 \%$ (night terrors: $2.2 \%$, sleep walking: $2 \%$, confusional arousals: $4.2 \%$ ) and REM parasomnias between 0.38 and $1.34 \%{ }^{85,86}$ The prevalence of parasomnia in renal disease has also been studied. Of the simple parasomnias, only nocturnal leg cramps have been reported in patients with CKD. Simple leg cramps in sleep are usually due to the electrolyte imbalances as well as osmotic shift in dialysis disequilibrium syndrome in patients undergoing dialysis. ${ }^{87}$ The prevalence of complex parasomnias in patients with CKD has been reported by Ezzat and Mohab. ${ }^{14}$ According to them, $2 \%$ of the patients with HD were found to have sleepwalking, $13 \%$ had nightmares, and $2 \%$ had REM sleep behavior disorder (RBD). Similarly, $4 \%$ of the patients with CKD had sleepwalking, $3 \%$ had RBD, and $15 \%$ had nightmares. ${ }^{14}$ Most of the non-REM parasomnias were found to be common in children, which diminish with age. However, REM parasomnias usually happen with advancing age. It is hard to estimate the true prevalence of these parasomnias in patients with renal disease as studies are highly variable and nested to only one group of patients. Nevertheless, looking at the study by Trotti, the prevalence of RBD appears slightly more than that of general population which is about $0.4-0.5 \%{ }^{88}$ This is likely because of the smaller cohort and ethnic variability along with other possible confounding factors such as comorbid neurological disorders where the prevalence of RBD is high. RBD is one of the most complex parasomnias, which has serious potential for injury as well as commonly associated with alpha synucleiopathies including Parkinson's disease. ${ }^{89}$ Similar to general population, high clinical suspicion is required for the identification of RBD in patients with CKD. Clinicians should also look for any other cause of sleep disturbance 
related to abnormal behaviors during sleep other than what has been well reported. Sleep disturbance related to uremic pruritus have been well reported and as many as 50-90\% of the patients undergoing HD were found to have pruritus..$^{90-92}$ Recently, Nigam et al have suggested that in the absence of definitive dermatological disorders, patients could still have isolated episodes of itching and scratching during sleep. This has been called "sleep-related scratching" and could represent a distinct parasomnia in itself. ${ }^{93}$ It remains unclear if renal disorders and so-called "kidney clocks" have any insidious role to play in its genesis. Diligent attention should be paid while obtaining a thorough medical history in such patients who only have sleep-related pruritus without wakefulness daytime pruritus.

\section{Sleep-related movement disorders Restless legs syndrome}

Within the spectrum of sleep disorders, RLS causes a disturbance in sleep through an inexplicable desire to move one's legs. ${ }^{94,95}$ Possible etiologies in the development of RLS include but are not limited to low levels of iron, Parkinson's dementia, autoimmune disorders, hypothyroidism, peripheral neuropathy, and folate deficiency. ${ }^{94}$ In patients with CKD or ESRD, the correlation to an etiology of RLS appears to be related to iron deficiency. ${ }^{94-97}$ The need for dialysis could further exacerbate the iron deficiency thereby worsening RLS. ${ }^{98}$

As a consequence of CKD or ESRD and dialysis, the patient often develops an imbalance in various metabolites and bioelements. In addition, the patient also develops anemia due to various reasons including blood loss directly from the dialysis, frequent blood tests, and a decrease in the levels of erythropoietin. ${ }^{99-102}$ Because iron is bound to hemoglobin, a decrease in the count of red blood cells leads to a decrease in hemoglobin levels thereby causing a decrease in the levels of iron. ${ }^{100}$ Low levels of iron have been implicated as the primary cause of RLS and is directly linked to CKD and dialysis. ${ }^{8,16}$ A measurement of serum ferritin provides a definitive diagnosis as it relates to the levels of serum iron and has been implicated in anemia in case of chronic disease. ${ }^{94,95}$

Recently, several authors have studied the correlation between sleep disorders and CKD or ESRD. ${ }^{8-15}$ Within the spectrum of sleep disorders, RLS remains a prominent abnormality that develops as a result of CKD. ${ }^{8,9}$ Most researchers concur that dialysis most likely worsens iron deficiency and probably is one of the primary reasons for the development of RLS. ${ }^{16,94,95,100,101}$
Typically, definitive treatment of any disease requires resolution of the cause. By the time that a patient requires dialysis, normal kidney function is unlikely to be restored medically and therefore sometimes may require kidney transplantation (as a result of hemodynamic and metabolic abnormalities, along with worsening RLS in patients with ESRD). A temporary treatment until transplantation involves use of dopamine agonists, but this often fails to fully resolve RLS. ${ }^{94,95}$ One study suggests that parathyroidectomy as the treatment of hypercalcemia in primary hyperparathyroidism could be a feasible technique to effectively manage and resolve RLS. ${ }^{102}$ Mortazavi et al provided data promoting aerobic exercise to manage RLS in patients with CKD on dialysis. ${ }^{103}$

\section{Conclusion}

Sleep disorders are intricately linked with both CKD and non-CKD-related renal disorders. Kidney disorders permeate the world of sleep medicine beyond the run-of-the-mill suspects such as OSA and RLS. In the past few years, many new definitive associations have been established between kidney diseases and sleep disorders. Obtaining a diligent history and prompt referral to a sleep medicine provider for further investigation is warranted at the earliest suspicion of an insidious sleep disorder. This appears to be a reasonable approach that can be followed by primary care providers when working with patients with kidney disorders.

\section{Author contributions}

All authors contributed toward data analysis, drafting and critically revising the paper and agree to be accountable for all aspects of the work. The views expressed in this abstract/ manuscript are those of the author(s) and do not reflect the official policy or position of the Department of the Army, Department of Defense, or the US Government.

\section{Disclosure}

This study was not supported by the industry. The views expressed herein are solely of the authors. The authors report no conflicts of interest in this work.

\section{References}

1. Stevens PE, Levin A; Kidney Disease: Improving Global Outcomes Chronic Kidney Disease Guideline Development Work Group Members. Evaluation and management of chronic kidney disease: synopsis of the kidney disease: improving global outcomes 2012 clinical practice guideline. Ann Intern Med. 2013;158(11):825-830.

2. Aritake-Okada S, Nakao T, Komada Y, et al. Prevalence and clinical characteristics of restless legs syndrome in chronic kidney disease patients. Sleep Med. 2011;12(10):1031-1033. 
3. Adeseun GA, Rosas SE. The impact of obstructive sleep apnea on chronic kidney disease. Curr Hypertens Rep. 2010;12(5):378-383.

4. Plantinga L, Lee K, Inker LA, et al; CDC CKD Surveillance Team. Association of sleep-related problems with CKD in the United States, 2005-2008. Am J Kidney Dis. 2011;58(4):554-564.

5. ICSD-3 Online Version - American Academy of Sleep Medicine (AASM). 2016 National sleep medicine course bundle. Available from: http://www.aasmnet.org/store/product.aspx?pid=849. Accessed March 30, 2015.

6. Roth T. Insomnia: definition, prevalence, etiology, and consequences. J Clin Sleep Med. 2007;3(5 Suppl):S7-S10.

7. Bonnet MH. Evidence for the pathophysiology of insomnia. Sleep. 2009;32(4):441-442.

8. De Santo RM, Bartiromo M, Cesare MC, Di Iorio BR. Sleeping disorders in early chronic kidney disease. Semin Nephrol. 2006;26(1): 64-67.

9. Maung SC, El Sara A, Chapman C, Cohen D, Cukor D. Sleep disorders and chronic kidney disease. World J Nephrol. 2016;5(3):224-232.

10. Pierratos A, Hanly PJ. Sleep disorders over the full range of chronic kidney disease. Blood Purif. 2011;31(1-3):146-150.

11. Lin HY, Hung CC, Chang YH, et al. Nonapnea sleep disorders in patients younger than 65 years are significantly associated with CKD: a nationwide population-based study. PLoS One. 2015;10(10):e140401.

12. Hanly P. Sleep disorders and end-stage renal disease. Curr Opin Pulm Med. 2008;14(6):543-550.

13. De Santo RM, Perna A, Di Iorio BR, Cirillo M. Sleep disorders in kidney disease. Minerva Urol Nefrol. 2010;62(1):111-128.

14. Ezzat H, Mohab A. Prevalence of sleep disorders among ESRD patients. Ren Fail. 2015;37(6):1013-1019.

15. Ibrahim JM, Wegdan OM. Epidemiology of sleep disorders in patients with chronic renal disease in Cairo, Egypt. $J$ Egypt Public Health Assoc. 2011;86(3-4):68-72.

16. Parker KP. Sleep and dialysis: a research-based review of the literature. Anna J. 1997;24(6):626-639; quiz 640-641.

17. Pai MF, Hsu SP, Yang SY, Ho TI, Lai CF, Peng YS. Sleep disturbance in chronic hemodialysis patients: the impact of depression and anemia. Ren Fail. 2007;29(6):673-677.

18. Merlino G, Gigli GL, Valente M. Sleep disturbances in dialysis patients. J Nephrol. 2008;(21 Suppl)13:S66-S70.

19. Kosmadakis GC, Medcalf JF. Sleep disorders in dialysis patients. Int J Artif Organs. 2008;31(11):919-927.

20. Novak M, Shapiro CM, Mendelssohn D, Mucsi I. Reviews: Diagnosis and management of insomnia in dialysis patients. Semin Dial. 2006;19(1):25-31.

21. Merlino G, Piani A, Dolso P, et al. Sleep disorders in patients with end-stage renal disease undergoing dialysis therapy. Nephrol Dial Transplant. 2006;21(1):184-190.

22. Perl J, Unruh ML, Chan CT. Sleep disorders in end-stage renal disease: 'Markers of inadequate dialysis?' Kidney Int. 2006;70(10): $1687-1693$.

23. Losso RL, Minhoto GR, Riella MC. Sleep disorders in patients with end-stage renal disease undergoing dialysis: comparison between hemodialysis, continuous ambulatory peritoneal dialysis and automated peritoneal dialysis. Int Urol Nephrol. 2015;47(2):369-375.

24. Knezevic MZ, Djordjevic VV, Jankovic SM, Djordjevic VM. Influence of dialysis modality and membrane flux on insomnia severity in haemodialysis patients. Nephrology (Carlton). 2013;18(11):706-711.

25. Rayner HC. Orexin as a possible cause of insomnia in dialysis patients. Am J Kidney Dis. 2003;41(6):1335-1336; author reply 1336.

26. Sutcliffe JG, de Lecea L. The hypocretins: excitatory neuromodulatory peptides for multiple homeostatic systems, including sleep and feeding. J Neurosci Res. 2000;62(2):161-168.

27. Marcus JN, Elmquist JK. Orexin projections and localization of orexin receptors. In: Nishino S, Sakurai T, editors. The Orexin/Hypocretin System. Totowa, NJ: Humana Press Inc; 2006.

28. Virga G, Stanic L, Mastrosimone S, Gastaldon F, da Porto A, Bonadonna A. Hypercalcemia and insomnia in hemodialysis patients. Nephron. 2000;85(1):94-95.
29. Minisola S, Pepe J, Piemonte S, Cipriani C. The diagnosis and management of hypercalcaemia. BMJ. 2015;350:h2723.

30. Esposito MG, Cesare CM, De Santo RM, et al. Parathyroidectomy improves the quality of sleep in maintenance hemodialysis patients with severe hyperparathyroidism. $J$ Nephrol. 2008;21(Suppl 13): S92-S96.

31. Ohno K, Sakurai T. Orexin neuronal circuitry: role in the regulation of sleep and wakefulness. Front Neuroendocrinol. 2008;29(1):70-87.

32. Dou L, Lan H, Reynolds DJ, et al. Association between obstructive sleep apnea and acute kidney injury in critically ill patients: a propensity-matched study. Nephron. 2017;135(2):137-146.

33. Kuhlmann U, Becker HF, Birkhahn M, et al. Sleep-apnea in patients with end-stage renal disease and objective results. Clin Nephrol. 2000;53(6):460-466.

34. Adams RJ, Appleton SL, Vakulin A, et al. Chronic kidney disease and sleep apnea association of kidney disease with obstructive sleep apnea in a population study of men. Sleep. 2017;40(1).

35. Camacho M, Capasso R, Schendel S. Airway changes in obstructive sleep apnoea patients associated with a supine versus an upright position examined using cone beam computed tomography. $J$ Laryngol Otol. 2014;128(9):824-830.

36. Elias RM, Bradley TD, Kasai T, Motwani SS, Chan CT. Rostral overnight fluid shift in end-stage renal disease: relationship with obstructive sleep apnea. Nephrol Dial Transplant. 2012;27(4):1569-1573.

37. Beecroft JM, Hoffstein V, Pierratos A, Chan CT, McFarlane P, Hanly PJ. Nocturnal haemodialysis increases pharyngeal size in patients with sleep apnoea and end-stage renal disease. Nephrol Dial Transplant. 2008;23(2):673-679.

38. Lee JJ, Kim GS, Kim JA, et al. Improvement of sleep-related breathing disorder in patients with end-stage renal disease after kidney transplantation. Clin Transplant. 2011;25(1):126-130.

39. Tang SC, Lam B, Lam JC, et al. Impact of nephrotic edema of the lower limbs on obstructive sleep apnea: gathering a unifying concept for the pathogenetic role of nocturnal rostral fluid shift. Nephrol Dial Transplant. 2012;27(7):2788-2794.

40. Berry RB, Budhiraja R, Gottlieb DJ, et al; American Academy of Sleep Medicine. Rules for scoring respiratory events in sleep: update of the 2007 AASM manual for the scoring of sleep and associated events: deliberations of the sleep apnea definitions task force of the American Academy of Sleep Medicine. J Clin Sleep Med. 2012;8(5): 597-619.

41. Adrogué HE, Adrogué HJ. Acid-base physiology. Respir Care. 2001;46(4):328-341.

42. Böing S, Randerath WJ. Chronic hypoventilation syndromes and sleep-related hypoventilation. J Thorac Dis. 2015;7(8):1273-1285.

43. Hall IE, Kashgarian M, Moeckel GW, Dahl NK. Resolution of proteinuria in a patient with focal segmental glomerulosclerosis following BiPAP initiation for obesity hypoventilation syndrome. Clin Nephrol. 2012;77(1):62-65.

44. Nigam G, Riaz M. Pathophysiology of central sleep apnea in chronic kidney disease. Saudi J Kidney Dis Transpl. 2016;27(5):1068-1070.

45. Nigam G, Pathak C, Riaz M. A systematic review of central sleep apnea in adult patients with chronic kidney disease. Sleep Breath. 2016;20(3): 957-964.

46. Nigam G, Riaz M. Probing the prevalence of central sleep apnea in patients with chronic kidney disease. Sleep Breath. 2016;20(4): 1275-1276.

47. Fleischmann G, Fillafer G, Matterer H, Skrabal F, Kotanko P. Prevalence of chronic kidney disease in patients with suspected sleep apnoea. Nephrol Dial Transplant. 2010;25(1):181-186.

48. Tada T, Kusano KF, Ogawa A, et al. The predictors of central and obstructive sleep apnoea in haemodialysis patients. Nephrol Dial Transplant. 2007;22(4):1190-1197.

49. Kimmel PL, Miller G, Mendelson WB. Sleep apnea syndrome in chronic renal disease. Am J Med. 1989;86(3):308-314.

50. Xu J, Yoon IY, Chin HJ. The effect of sleep apnea on all-cause mortality in nondialyzed chronic kidney disease patients. Sleep Med. 2016;27-28:32-38. 
51. Hanly PJ, Pierratos A. Improvement of sleep apnea in patients with chronic renal failure who undergo nocturnal hemodialysis. $N$ Engl J Med. 2001;344(2):102-107.

52. Burkhalter H, Wirz-Justice A, Cajochen C, et al. Daytime sleepiness in renal transplant recipients is associated with immunosuppressive non-adherence: a cross-sectional, multi-center study. Clin Transplant. 2014;28(1):58-66.

53. Baba Y, Higuchi MA, Fukuyama K, et al. Effect of chronic kidney disease on excessive daytime sleepiness in Parkinson disease. Eur J Neurol. 2011;18(11):1299-1303.

54. Tanaka S, Honda M, Toyoda H, Kodama T. Increased plasma IL-6, IL-8, TNF-alpha, and G-CSF in Japanese narcolepsy. Hum Immunol. 2014;75(8):940-944.

55. Gohda T, Maruyama S, Kamei N, et al. Circulating TNF receptors 1 and 2 predict mortality in patients with end-stage renal disease undergoing dialysis. Sci Rep. 2017;7:43520.

56. Unruh ML, Sanders MH, Redline S, et al. Sleep apnea in patients on conventional thrice-weekly hemodialysis: comparison with matched controls from the Sleep Heart Health Study. J Am Soc Nephrol. 2006;17(12):3503-3509.

57. Walker S, Fine A, Kryger MH. Sleep complaints are common in a dialysis unit. Am J Kidney Dis. 1995;26(5):751-756.

58. Al-Jahdali H. Prevalence of sleep apnea and excessive day time sleepiness in patients with end-stage renal disease on dialysis. Saudi J Kidney Dis Transpl. 2012;23(2):251-261.

59. Burkhalter H, Wirz-Justice A, Cajochen C, et al. Validation of a single item to assess daytime sleepiness for the Swiss Transplant Cohort Study. Prog Transplant. 2013;23(3):220-228.

60. Hanly PJ, Gabor JY, Chan C, Pierratos A. Daytime sleepiness in patients with CRF: impact of nocturnal hemodialysis. Am J Kidney Dis. 2003;41(2):403-410.

61. Jurado-Gamez B, Martin-Malo A, Alvarez-Lara MA, Muñoz L, Cosano A, Aljama P. Sleep disorders are underdiagnosed in patients on maintenance hemodialysis. Nephron Clin Pract. 2007;105(1):c35-c42.

62. Parker KP, Bliwise DL, Bailey JL, Rye DB. Daytime sleepiness in stable hemodialysis patients. Am J Kidney Dis. 2003;41(2):394-402.

63. Davis ID, Baron J, O'riordan MA, Rosen CL. Sleep disturbances in pediatric dialysis patients. Pediatr Nephrol. 2005;20(1):69-75.

64. Iseki K, Tsuruya K, Kanda E, Nomura T, Hirakata H. Effects of sleepiness on survival in Japanese hemodialysis patients: J-DOPPS study. Nephron Clin Pract. 2014;128(3-4):333-340.

65. Gul A, Aoun N, Trayner EM Jr. Why do patients sleep on dialysis? Semin Dial. 2006;19(2):152-157.

66. Teles F, Azevedo VF, Miranda CT, Miranda MP, Teixeira Mdo C, Elias RM. Depression in hemodialysis patients: the role of dialysis shift. Clinics (Sao Paulo). 2014;69(3):198-202.

67. Smith E. Health and Disease, as Influenced by the Daily, Seasonal, and other Cyclical Changes in the Human System. London: Walton and Maberly; 1861.

68. Mills JN, Stanbury SW. Persistent 24-hour renal excretory rhythm on a 12-hour cycle of activity. J Physiol. 1952;117(1):22-37.

69. Wu T, Ni Y, Dong Y, et al. Regulation of circadian gene expression in the kidney by light and food cues in rats. Am J Physiol Regul Integr Comp Physiol. 2010;298(3):R635-R641.

70. Burkhalter H, De Geest S, Wirz-Justice A, Cajochen C. Melatonin rhythms in renal transplant recipients with sleep-wake disturbances. Chronobiol Int. 2016;33(7):810-820.

71. Koch BC, van der Putten K, Van Someren EJ, et al. Impairment of endogenous melatonin rhythm is related to the degree of chronic kidney disease (CREAM study). Nephrol Dial Transplant. 2010;25(2):513-519.

72. Viljoen M, Steyn ME, van Rensburg BW, Reinach SG. Melatonin in chronic renal failure. Nephron. 1992;60(2):138-143.

73. Koch BC, Nagtegaal JE, Hagen EC, Wee PM, Kerkhof GA. Different melatonin rhythms and sleep-wake rhythms in patients on peritoneal dialysis, daytime hemodialysis and nocturnal hemodialysis. Sleep Med. 2010;11(3):242-246.
74. Koch BC, Hagen EC, Nagtegaal JE, Boringa JB, Kerkhof GA, Ter Wee PM. Effects of nocturnal hemodialysis on melatonin rhythm and sleep-wake behavior: an uncontrolled trial. Am J Kidney Dis. 2009;53(4):658-664.

75. Możdżan M, Możdżan M, Chałubiński M, Wojdan K, Broncel M. The effect of melatonin on circadian blood pressure in patients with type 2 diabetes and essential hypertension. Arch Med Sci. 2014;10(4):669-675.

76. Levey A, Atkins R, Coresh J, et al. Chronic kidney disease as a global public health problem: approaches and initiatives-a position statement from Kidney Disease Improving Global Outcomes. Kidney Int. 2007;72(3):247-259.

77. Canuto R, GarcezAS, Olinto MT. Metabolic syndrome and shift work: a systematic review. Sleep Med Rev. 2013;17(6):425-431.

78. Yu KH, Yi YH, Kim YJ, et al. Shift work is associated with metabolic syndrome in young female Korean workers. Korean J Fam Med. 2017;38(2):51-56.

79. Guo Y, Rong Y, Huang X, et al. Shift work and the relationship with metabolic syndrome in Chinese aged workers. PLoS One. 2015;10(3):e0120632.

80. Kawabe Y, Nakamura Y, Kikuchi S, et al. Relationship between shift work and clustering of the metabolic syndrome diagnostic components. J Atheroscler Thromb. 2014;21(7):703-711.

81. Wang F, Zhang L, Zhang Y, et al. 0147 meta-analysis on night shift work and risk of metabolic syndrome. Occup Environ Med. 2014;71(Suppl 1):A78.

82. Mahowald MW, Schenck CH. Insights from studying human sleep disorders. Nature. 2005;437(7063):1279-1285.

83. Hublin C, Kaprio J. Genetic aspects and genetic epidemiology of parasomnias. Sleep Med Rev. 2003;7(5):413-421.

84. Oswald I. Sleep mechanisms: recent advances. Proc $R$ Soc Med. 1962;55:910-912.

85. Howell MJ. Parasomnias: an updated review. Neurotherapeutics. 2012;9(4):753-775.

86. Ohayon MM, Guilleminault C, Priest RG. Night terrors, sleepwalking, and confusional arousals in the general population: their frequency and relationship to other sleep and mental disorders. J Clin Psychiatry. 1999;60(4):268-276; quiz 277.

87. Silver SM, Sterns RH, Halperin ML. Brain swelling after dialysis: old urea or new osmoles? Am J Kidney Dis. 1996;28(1):1-13.

88. Trotti LM. REM sleep behaviour disorder in older individuals: epidemiology, pathophysiology and management. Drugs Aging. 2010;27(6):457-470.

89. Schenck CH, Boeve BF, Mahowald MW. Delayed emergence of a parkinsonian disorder or dementia in $81 \%$ of older men initially diagnosed with idiopathic rapid eye movement sleep behavior disorder: a 16-year update on a previously reported series. Sleep Med. 2013;14(8): 744-748.

90. Suseł J, Batycka-Baran A, Reich A, Szepietowski JC. Uraemic pruritus markedly affects the quality of life and depressive symptoms in haemodialysis patients with end-stage renal disease. Acta Derm Venereol. 2014;94(3):276-281.

91. Lugon JR. Uremic pruritus: a review. Hemodial Int. 2005;9(2):180-188.

92. Jaiswal D, Uzans D, Hayden J, Kiberd BA, Tennankore KK. Targeting the opioid pathway for uremic pruritus: a systematic review and meta-analysis. Can J Kidney Health Dis. 2016;3:2054358116675345.

93. Nigam G, Riaz M, Hershner SD, Goldstein CA, Chervin RD. Sleep related scratching: a distinct parasomnia? J Clin Sleep Med. 2016;12(1): 139-142.

94. Allen RP, Picchietti D, Hening WA, Trenkwalder C, Walters AS, Montplaisi J; Restless Legs Syndrome Diagnosis and Epidemiology workshop at the National Institutes of Health; International Restless Legs Syndrome Study Group. Restless legs syndrome: diagnostic criteria, special considerations, and epidemiology. A report from the restless legs syndrome diagnosis and epidemiology workshop at the National Institutes of Health. Sleep Med. 2003;4(2):101-119. 
95. Yücel M, Akgün H, Oz O, Demirkaya S. Migraine and restless leg syndrome co-morbidity may be due to iron deficiency. Ann Indian Acad Neurol. 2013;16(3):461.

96. Gigli GL, Adorati M, Dolso P, et al. Restless legs syndrome in endstage renal disease. Sleep Med. 2004;5(3):309-315.

97. Lee J, Nicholl DD, Ahmed SB, et al. The prevalence of restless legs syndrome across the full spectrum of kidney disease. J Clin Sleep Med. 2013;9(5):455-459.

98. Kavanagh D, Siddiqui S, Geddes CC. Restless legs syndrome in patients on dialysis. Am J Kidney Dis. 2004;43(5):763-771.

99. Fonseca NT, Urbano JJ, Nacif SR, et al. A systematic review of sleep disorders in patients with chronic kidney disease undergoing hemodialysis. J Phys Ther Sci. 2016;28(7):2164-2170.
100. Beladi-Mousavi SS, Jafarizade M, Shayanpour S, Bahadoram M, Moosavian SM, Houshmand G. Restless legs syndrome: associated risk factors in hemodialysis patients. Nephrourol Mon. 2015;7(6):e31967.

101. Siddiqui S, Kavanagh D, Traynor J, Mak M, Deighan C, Geddes C. Risk factors for restless legs syndrome in dialysis patients. Nephron Clin Pract. 2005;101(3):c155-c160.

102. Santos RS, Coelho FM, Silva BC, et al. Parathyroidectomy improves restless leg syndrome in patients on hemodialysis. PLoS One. 2016;11(5): e0155835.

103. Mortazavi M, Vahdatpour B, Ghasempour A, et al. Aerobic exercise improves signs of restless leg syndrome in end stage renal disease patients suffering chronic hemodialysis. ScientificWorldJournal. 2013;2013:628142.

\section{Publish your work in this journal}

Nature and Science of Sleep is an international, peer-reviewed, open access journal covering all aspects of sleep science and sleep medicine, including the neurophysiology and functions of sleep, the genetics of sleep, sleep and society, biological rhythms, dreaming, sleep disorders and therapy, and strategies to optimize healthy sleep. The manuscript management system is completely online and includes a very quick and fair peer-review system, which is all easy to use. Visit http://www. dovepress.com/testimonials.php to read real quotes from published authors. 